\title{
APRENDIZAGEM, MENTORIA E CULTURA ORGANIZACIONAL DE APRENDIZAGEM: O ESTUDO DO CASO DA PERFORMANCE CONSULTORIA E AUDITORIA $^{1}$
}

\author{
Constantino de Carvalho Oliveira Neto ${ }^{2}$ \\ Jader Cristino de Souza-Silva ${ }^{3}$
}

http://dx.doi.org/10.1590/1413-2311.168.62959

\begin{abstract}
RESUMO
Na literatura sobre aprendizagem organizacional, alguns autores (DONALDSON; ENSHER; GRANT-VALLONE, 2000; BOZEMAN; FEENEY, 2007) sinalizam para o fato de que existem ambientes que são mais propícios que outros em relação ao desenvolvimento de processos de aprendizagem. Outros pesquisadores (JOO; LIM, 2009) afirmam que os valores e crenças presentes em uma cultura organizacional afetam como as pessoas reagem e se comportam em relação ao processo de aprendizagem. Ora, sendo a mentoria marcadamente uma modalidade de aprendizagem organizacional, pode-se presumir que a cultura é um forte elemento influenciador para que um contexto organizacional seja mais ou menos propício ao desenvolvimento da mentoria. Assim, o artigo tem como propósito investigar como a cultura organizacional influencia o processo de mentoria em uma empresa de consultoria e auditoria. A abordagem da pesquisa empírica foi fundamentalmente qualitativa, tendo sido adotado o estudo de caso simples e a análise do discurso do sujeito coletivo (DSC), visando à interpretação dos achados empíricos. Como resultado e resposta ao problema dessa investigação constataram-se, na organização estudada, três categorias de valores que exercem forte influência no surgimento e desenvolvimento de mentorias, a saber, valores ligados à valorização do desenvolvimento técnico-profissional, da interação social e do ser humano.
\end{abstract}

Palavras-chave: Mentoria. Cultura Organizacional de Aprendizagem. Aprendizagem Organizacional.

\section{LEARNING, MENTORING AND ORGANIZATIONAL CULTURE OF LEARNING: THE CASE STUDY OF PERFORMANCE CONSULTING AND AUDIT}

\author{
ABSTRACT \\ In the literature on organizational learning, some authors (DONALDSON; ENSHER; \\ GRANT-VALLONE, 2000; BOZEMAN; FEENEY, 2007) indicate that there are

\footnotetext{
${ }^{1}$ Recebido em 11/03/2016; aprovado em 26/06/2017.

${ }^{2}$ Unime Salvador - constantino.oliveira@ yahoo.com.br.

${ }^{3}$ Universidade do Estado da Bahia - falecom@jadersouza.com.br. REAd | Porto Alegre - Vol. 23 - Nº Especial - Dezembro 2017 - p. 60-92
} 
environments that are more conducive than others to the development of learning processes. Other researchers (JOO; LIM, 2009) argue that the values and beliefs present in an organizational culture affect how people react and behave in relation to the organizational learning process. Since mentoring is markedly an organizational learning modality, it can be assumed that culture is a strong influencing element for having an organizational context that is more or less conducive to the development of mentoring. Thus, the article aims to investigate how the organizational culture influences the process of mentoring in a consulting and auditing company. The empirical research approach was fundamentally qualitative, having adopted the simple case study and the analysis of the discourse of the collective subject (DSC), aiming interpretation of the empirical findings. As a result, three categories of values that exerted a strong influence on the emergence and development of mentoring were found in the organization studied: values linked to the valorization of technical and professional development, social interaction and human being.

Keywords: Mentoring. Organizational Culture of Learning. Organizational Learning.

\section{APRENDIZAJE, TUTORÍA Y CULTURA ORGANIZACIONAL DE APRENDIZAJE: EL ESTUDIO DE CASO DE LA PERFORMANCE CONSULTORÍA Y AUDITORÍA}

\section{RESUMEN}

En la literatura sobre aprendizaje organizacional, algunos autores señalan al hecho de que hay entornos de organización que son más propicios que otros para el desarrollo de procesos de aprendizaje (DONALDSON; ENSHER; GRANT-VALLONE, 2000; BOZEMAN; FEENEY, 2007). Otros investigadores (JOO; LIM, 2009) afirman que los valores y las creencias presentes en una cultura organizacional afectan cómo las personas reaccionan y se comportan en relación con el proceso de aprendizaje de la organización. Como la tutoría es notablemente una forma de aprendizaje organizacional, se puede suponer que la cultura organizacional es un fuerte elemento de influencia para un contexto organizacional ser más o menos propicio para el desarrollo de la tutoría. Por lo tanto, el artículo tiene como objetivo investigar cómo la cultura organizacional influye en el proceso de tutoría en una empresa de consultoría y auditoría. El enfoque de la investigación empírica fue principalmente cualitativo, habiendo adoptado el estudio de caso individual y el análisis del discurso del sujeto colectivo (DSC) para la interpretación de los resultados empíricos. Como resultado, la respuesta al problema de esta investigación encontró, en la organización estudiada, tres categorías de valores que tienen una fuerte influencia en la aparición y desarrollo de la tutoría, a saber, valores vinculados a la apreciación del desarrollo técnico y profesional, a la mejora de la interacción social y a la apreciación del ser humano.

Palabras-clave: Tutoría. Cultura Organizacional de Aprendizaje. Aprendizaje organizacional.

\section{INTRODUÇÃO}

A aprendizagem organizacional tem sido compreendida como fundamental para o REAd | Porto Alegre - Vol. 23 - No Especial - Dezembro 2017 - p. 60-92 
processo de sobrevivência e continuidade de empresas em ambientes cada vez mais mutantes e competitivos (BINGHAM; DAVIS, 2012; BERTOLIN; ZWICK; BRITO, 2013). Assim sendo, a aprendizagem organizacional assume um papel estratégico e pode ser entendida como um processo pelo qual uma organização desenvolve competências e qualifica os seus profissionais (GHERARDI, NICOLINI; ODELLA, 1998; WANG; AHMED, 2000; FITZSIMMONS, 2011).

Uma das modalidades que tem se tornado crucial no processo de aprendizagem organizacional é a mentoria (SOUZA-SILVA, 2007; GUEIROS, 2012; DOS-SANTOS, et al., 2015). Observa-se que as mentorias estão presentes em muitos programas de educação corporativa e desenvolvimento humano nas organizações (SWAP et al.., 2001; ENSHER; MURPHY, 2011). Por exemplo, aproximadamente 70\% das 500 maiores empresas dos Estados Unidos oferecem algum tipo de programa formal de mentoria para os seus funcionários (GUTNER, 2009). O interesse e a quantidade de pesquisas acadêmicas em torno do tema são bastante significativos na literatura internacional e na nacional (LESTER et al., 2011; GUEIROS, 2012).

Nos escritos sobre aprendizagem organizacional, muitos autores (DONALDSON; ENSHER; GRANT-VALLONE, 2000; BOZEMAN; FEENEY, 2007) sinalizam para o fato de que existem ambientes organizacionais que são mais propícios do que outros em relação ao desenvolvimento de processos de aprendizagem (EGAN; YANG; BARTLETT, 2004). Outros pesquisadores (WANG; AHMED, 2003; ELLIS; SHIPIELBER, 2003; SOUZA-SILVA, 2007; JOO; LIM, 2009) afirmam que os valores e crenças presentes numa cultura organizacional afetam como as pessoas reagem e se comportam em relação ao processo de aprendizagem organizacional.

Ora, sendo a mentoria uma modalidade de aprendizagem organizacional (ALMEIDA; SOUZA-SILVA, 2015; DOS-SANTOS, et al., 2015), pode-se presumir que a cultura organizacional é um forte elemento influenciador para que um contexto organizacional seja mais ou menos propício ao desenvolvimento da mentoria.

Neste sentido, estudar a cultura organizacional pode ser um interessante caminho para entender a emergência e desenvolvimento de programas de mentoria no universo organizacional. Assim, o objetivo deste artigo é investigar como a cultura organizacional influencia o processo de mentoria em uma organização de consultoria e auditoria. Entender, mais profundamente, os fatores que contribuem para a aprendizagem nas organizações e, em específico, o papel da cultura organizacional, é estratégico em um momento em que o REAd | Porto Alegre - Vol. 23 - No Especial - Dezembro 2017 - p. 60-92 
conhecimento assume centralidade para o sucesso em um contexto organizacional cada vez mais competitivo.

Para levar a cabo o objetivo desta pesquisa, foi realizado um estudo de caso na empresa Performance: Auditoria e Consultoria que representa um campo fértil para se aprofundar no fenômeno em questão: a mentoria. Neste sentido, este artigo está dividido em cinco partes, sendo que a primeira se refere à esta Introdução. A segunda trata do referencial teórico que discorreu sobre os construtos essenciais a esta investigação: mentoria e cultura organizacional de aprendizagem. A terceira parte refere-se à metodologia de pesquisa que assumiu um caráter qualitativo, utilizando o estudo de caso simples e o discurso do sujeito coletivo como estratégias metodológicas. A quarta parte foi reservada à análise dos resultados da pesquisa e a quinta e última seção trata das conclusões desta investigação.

\section{REFERENCIAL TEÓRICO}

\subsection{DA APRENDIZAGEM ORGANIZACIONAL À MENTORIA}

Antes de se aprofundar o conceito de mentoria é relevante refletir sobre a sua relação com o fenômeno da aprendizagem organizacional. Neste sentido, Dos-Santos et al. (2015) salientam que o construto da aprendizagem organizacional contempla uma variedade de perspectivas, concepções e abordagens (SOUZA-SILVA, 2009; ILLERIS, 2013). Apesar disso, Dos-Santos et al. (2015), com base em alguns outros autores (COOK; BROWN, 1999; AZEVEDO, 2012), procuram entender a aprendizagem organizacional a partir de duas concepções essenciais: a epistemologia da posse e a epistemologia da prática.

A epistemologia da posse entende o conhecimento como algo que as pessoas possuem (COOK; BROWN, 1999); um bem e não um processo, sendo que o mesmo pode ser transmitido e estocado, acontecendo, sobretudo, na mente dos indivíduos (NICOLINI; GHERARDI; YANOW, 2003). Já a epistemologia da prática concebe a construção do conhecimento a partir da prática, por meio da experiência do fazer individual ou grupal. Quando em grupo, o aprendizado ocorre, também, através da interação entre as pessoas e na consequente troca de significados e intercâmbios de informações (NICOLINI; GHERARDI; YANOW, 2003; DOS-SANTOS et al.; 2015).

Tais concepções gestam, na literatura da aprendizagem organizacional, duas abordagens: a individual cognitiva e a socioprática (WENGER, 1998; REAd | Porto Alegre - Vol. 23 - No Especial - Dezembro 2017 - p. 60-92 
ANTONACOPOULOU, 2000; GHERARDI, 2013; ALMEIDA; SOUZA-SILVA, 2015; BRITO-DE-JESUS et al., 2016).

A abordagem individual cognitiva inspira-se na concepção da epistemologia da posse. Nesta abordagem, o conhecimento é compreendido como sendo de natureza codificada e cognitiva. O conhecimento codificado trata-se daquele no qual a informação é traduzida por meio de uma comunicação explícita, com base em símbolos e sinais convencionais. $\mathrm{O}$ conhecimento cognitivo é entendido como dependente de talentos conceituais e competências cognitivas, podendo ser denominado de conhecimento abstrato (SOUZA-SILVA, 2009).

Já para abordagem socioprática, o conhecimento é prático, sócio-relacional e integralmente tácito e explícito. Ele é prático, pois é adquirido por meio da ação, sendo que precisa da presença física da pessoa para que as informações sejam melhor entendidas não apenas cognitivamente, mas sensorialmente. Além disso, ele é prático porque está associado às rotinas organizacionais que exploram os relacionamentos entre a tecnologia, papéis e procedimentos formais e processos emergentes (SOUZA-SILVA, 2009). O conhecimento é sóciorrelacional, pois reside na dinâmica do relacionamento social que ocorre como fruto do cotidiano do próprio contexto organizacional no decurso das atividades profissionais (ALVESSON; KÄRREMAN, 2001; ALMEIDA; SOUZA-SILVA, 2015). Assim, o conhecimento é disseminado a partir dos fenômenos sociais e interacionistas, do intercâmbio de significados e da partilha de experiências no próprio contexto organizacional. Finalmente, o conhecimento é integralmente explícito e tácito porque contempla as duas naturezas que lhe compõem (POLANYI, 1996; BROWN; DUGUID, 1991; SOUZA-SILVA, 2009). A dimensão explícita do conhecimento é aquela que pode ser transformada em códigos e, bem por isso, pode ser transmitida em linguagem sistemática e formal. Tal dimensão representa somente uma porção da totalidade do conhecimento. Por sua vez, a dimensão tácita é subjetiva, tornando-a, dessa maneira, mais difícil de formalizar e comunicar de forma explícita (SOUZA-SILVA, 2007; SANTANA; SOUZA-SILVA, 2012).

Cada uma dessas abordagens possui modalidades de aprendizagem. A abordagem individual cognitiva apresenta como modalidades o treinamento tradicional, a leitura de textos e o acesso aos bancos de dados. Já as modalidades de aprendizagem na abordagem socioprática são comunidades de prática, interações casuais, treinamento on-the-job e a mentoria (DOS-SANTOS et al. 2015).

Portanto, com base nesse breve panorama, percebe-se a mentoria como sendo um fenômeno associado aos processos de aprendizagem organizacional, sendo mais REAd | Porto Alegre - Vol. 23 - No Especial - Dezembro 2017 - p. 60-92 
especificamente uma modalidade da abordagem socioprática de aprendizagem organizacional.

\subsection{CONCEITOS DE MENTORIA}

O conceito de mentoria é originado de um arquétipo antigo da mitologia grega. Personagem na Odisséia de Homero, o Mentor era um conselheiro sábio e de confiança que deveria proteger o filho de Odisseu (Ulisses em latim), Telêmaco, enquanto ele navegava contra Tróia (RAGINS; KRAM, 2007).

No campo organizacional, a mentoria representa um relacionamento entre um profissional mais experiente (mentor) e outro menos experiente (discípulo, mentorado, protégé) com o propósito de fomentar, sobretudo, o desenvolvimento deste último na prática laboral. Nessa relação de mentoria, o protégé vai adquirindo competências, autoconfiança e comportamentos profissionais positivos que têm o objetivo de contribuir com o processo de tomada de decisões quanto aos seus objetivos e sua trajetória profissional (KRAM; ISABELLA, 1985; REKHA; GANESH, 2012).

Mesmo sem possuir um trabalho específico que se possa dizer categoricamente que é o início das pesquisas de mentoria, pode-se afirmar que o artigo de Kram (1983) é o embrião da tradição das pesquisas contemporâneas na área. Tal autora define o processo de mentoria como a relação entre um jovem profissional (protégé) com outro profissional sênior (mentor), com muito mais experiência, no intuito de oferecer suporte à carreira, bem como apoio psicossocial. Outros autores (KRAM; ISABELLA, 1985; RAGINS, 1997; MERTZ, 2004) trazem complementações ao conceito de mentoria e as funções de mentor. Por exemplo, Scandura (1992) agrega a difundida noção de que o mentor deve prover o suporte profissional e psicossocial, introduzindo o papel de modelo (role model) como uma terceira função.

Para a finalidade desse trabalho e utilização de uma conceituação mais abrangente, a definição de Ensher e Murphy (2011, p.253) parece ser a mais propícia para o número de possibilidades que se oferece na literatura especializada: "O mentor é definido como a pessoa, em uma rede de relacionamento, que oferece suporte emocional, suporte de carreira e que serve de modelo".

\subsection{TIPOS DE MENTORIA}

A partir da revisão da literatura nacional e internacional sobre mentoria, chegou-se a REAd | Porto Alegre - Vol. 23 - No Especial - Dezembro 2017 - p. 60-92 
uma variedade de tipos de mentoria de acordo com o Quadro 1.

A mentoria pode ser compreendida em relação à rede de relacionamentos, à formalização, à hierarquia e ao contexto.

No que tange à rede de relacionamentos, a mentoria pode ser receptiva, tradicional, oportunista e empreendedora (CHAO; WALZ; GARDNER, 1992; RAGINS; COTTON, 1999; RAGINS; COTTON; MILLER, 2000). Tal perspectiva pode ser melhor compreendida a partir de dois elementos caracterizadores: a intensidade da relação de mentoria e a diversidade dos relacionamentos. A intensidade da relação diz respeito à quão forte é o relacionamento entre o mentor e o protégé. Quanto à diversidade dos relacionamentos, os autores levam em conta a quantidade de mentores para cada protégé, bem como a redundância na transmissão da informação/conhecimento do mentor para o mentorando. Entende-se por redundância a semelhança de conteúdo oferecida pelos mentores. Na mentoria receptiva, há um ou poucos mentores para um protégé; além disso, os conhecimentos transferidos para o protégé pelos mentores são redundantes entre si. A ligação do protégé com os mentores não é forte.

\begin{tabular}{|l|l|l|}
\multicolumn{2}{|c|}{ Quadro 1 - Tipos de Mentorias e suas Categorias } \\
\hline \multicolumn{1}{|c|}{ Tipos de Mentoria } & \multicolumn{1}{|c|}{ Categorias } & \multicolumn{1}{c|}{ Referencial Teórico } \\
\hline $\begin{array}{l}\text { Em Relação à Rede de } \\
\text { Relacionamentos }\end{array}$ & $\begin{array}{l}\text { Receptiva, Tradicional, } \\
\text { Oportunista e Empreendedora }\end{array}$ & Higgins e Kram (2001); Dobrow et al. (2012) \\
\hline Em Relação à Formalização & Formal e Informal & $\begin{array}{l}\text { Chao, Walz, e Gardner (1992); Ragins e } \\
\text { Cotton (1999); Ragins, Cotton e Miller (2000) }\end{array}$ \\
\hline Em Relação à Hierarquia & $\begin{array}{l}\text { Tradicional, Peer Mentoring, } \\
\text { Step ahead Mentoring }\end{array}$ & $\begin{array}{l}\text { Kram e Isabella (1985); Ensher, Thomas e } \\
\text { Murphy (2001) }\end{array}$ \\
\hline Em Relação ao Contexto & $\begin{array}{l}\text { Tradicional e Virtual (e- } \\
\text { mentoring) }\end{array}$ & $\begin{array}{l}\text { Ensher, Heun e Blanchard (2003); Hamilton e } \\
\text { Scandura (2003) }\end{array}$ \\
\hline
\end{tabular}

Fonte: elaborado pelos autores.

Na mentoria tradicional, há forte ligação entre o(s) mentor(es) e o protégé e há um ou poucos mentores para um protégé. Nessa categoria, havendo mais de um mentor, o nível de redundância das informações/conhecimento transmitidas por este para o protégé também é alta. A oportunista refere-se à forma passiva de o indivíduo receber a mentoria de diferentes mentores, em um determinado momento, sem um esforço ativo na construção de relacionamentos duradouros. Mesmo recebendo diferentes informações de diferentes mentores, se o protégé não procura apoio ativamente e não cultiva os relacionamentos, a tendência é que esses relacionamentos se enfraqueçam cada vez mais. Já que os mentores, nessa categoria, transmitem diferentes informações ao protégé, caracteriza-se baixa a 
redundância dos conhecimentos oferecidos. A forma empreendedora se embasa na compreensão de que um indivíduo pode se beneficiar de possuir fortes ligações com diferentes mentores simultaneamente. O empreendedor tem a característica de conseguir aglutinar uma grande diversidade de mentores e motivá-los a permanecer orientando-o, criando laços interpessoais fortes. Além disso, as informações transmitidas para o protégé não são redundantes (HIGGINS; KRAM, 2001; DOBROW et al.,2012).

Em relação à formalização, a mentoria pode ser formal ou informal. A mentoria formal, normalmente, é iniciada através de uma terceira parte (a organização) com o intuito de atingir os objetivos estabelecidos pela empresa. Por outro lado, a mentoria informal acontece através de um processo espontâneo de atração mútua entre o protégé e o mentor (CHAO; WALZ; GARDNER, 1992; ENSHER; MURPHY, 2011).

No que tange à hierarquia, a mentoria pode ser de três tipos: tradicional, step ahead mentoring e peer mentoring (PARKER; HALL; KRAM, 2008). A mentoria tradicional é quando o mentor está hierarquicamente muito acima do mentorando. Por exemplo, uma relação de mentoria que se estabelece entre um diretor e um trainee. O step ahead mentor é um indivíduo que está apenas em um nível hierárquico acima do protégé ou na posição que será o próximo passo profissional deste último, ou seja, a distância entre o mentor e o protégé é tênue, mas existe (ENSHER; MURPHY, 2011). Por último, no peer mentoring, o mentor está no mesmo nível hierárquico que o protégé. Ele funciona, porém, como um conselheiro, pois, normalmente, possui mais tempo de empresa que o mentorando, reunindo, assim, mais conhecimentos, habilidades e experiências sobre determinados procedimentos, tarefas e rotinas. Kram e Isabella (1985) advogam que devido à falta de uma dimensão hierárquica nesse relacionamento, a comunicação, o suporte mútuo e a colaboração se tornam muito mais fáceis.

Finalmente, em relação ao contexto, a mentoria pode ser tradicional ou virtual (HAMILTON; SCANDURA, 2003). Na mentoria virtual (também denominada de $e$ mentoring), usam-se os meios eletrônicos (chat, e-mail, skype e sites) como forma principal de comunicação entre o mentor e o protégé. Já na tradicional, o relacionamento acontece presencialmente, face a face (SMITH-JENTSCH et al., 2008).

Conforme visto, na introdução, o propósito deste paper é investigar como a cultura organizacional influencia o desenvolvimento de mentorias nas organizações. Ora, partindo daquilo que a literatura apregoa de que os valores e crenças presentes numa cultura organizacional afetam como as pessoas reagem e se comportam em relação à aprendizagem REAd | Porto Alegre - Vol. 23 - No Especial - Dezembro 2017 - p. 60-92 
organizacional e considerando a mentoria como uma modalidade de aprendizagem organizacional, pode-se presumir que a cultura de uma organização é um forte elemento influenciador para que um contexto organizacional seja mais ou menos propício ao desenvolvimento da mentoria. Nessa lógica, presume-se, também, que uma cultura organizacional de aprendizagem, isto é, aquela que possui valores e crenças que favoreçam a aprendizagem (KOFMAN; SENGE, 1995; WANG; AHMED, 2003; SOUZA-SILVA, 2007), pode ser um importante catalisador ao surgimento e desenvolvimento do processo de mentoria nas organizações. É sobre a cultura organizacional de aprendizagem que a seção seguinte se propõe a refletir.

\subsection{CULTURA ORGANIZACIONAL DE APRENDIZAGEM}

A cultura de uma empresa pode ser entendida como um conjunto de crenças, princípios e valores que influenciam o comportamento dos indivíduos nas organizações (SCHEIN, 1984). Já a noção de cultura organizacional de aprendizagem (KOFMAN; SENGE, 1995; WANG; AHMED, 2003; SOUZA-SILVA, 2007) relaciona os conceitos de cultura e aprendizagem, significando uma específica cultura capaz de criar condições propícias para intensificar a aprendizagem no ambiente organizacional. Foram identificadas, na literatura, alguns trabalhos que vinculam a noção de cultura à aprendizagem organizacional.

A pesquisa de Popper e Lipshitz (1998) sobre o processo de aprendizagem na Força Aérea Israelense amplia o entendimento de como a cultura organizacional favorece a aprendizagem numa organização. Tais autores cunham a noção de mecanismos de aprendizagem organizacional (organizational learning mechanisms) que se constituem em arranjos de atividades ricos em intercâmbio de conhecimentos entre as pessoas, bem como de promoção de aprendizagem. De acordo com eles, para que esses mecanismos de aprendizagem existam e para que a aprendizagem organizacional seja potencializada, requerse uma cultura organizacional apropriada e pautada em cinco essenciais valores hierarquizados (aprendizagem contínua, informação válida, transparência, orientação para a questão e responsabilidade pela aprendizagem). Neste sentido, esses cinco valores criam uma cultura de aprendizagem que influencia positivamente a existência desses mecanismos de aprendizagem organizacional (POPPER; LIPSHITZ, 1998).

$\mathrm{O}$ primeiro valor é a aprendizagem contínua (continuos learning) e diz respeito à crença de aprender continuamente em todos os momentos e situações do cotidiano REAd | Porto Alegre - Vol. 23 - No Especial - Dezembro 2017 - p. 60-92 
organizacional, promovendo não apenas a sobrevivência, mas a prosperidade organizacional. A aprendizagem contínua se sustenta em dois outros valores: a informação válida (valid information) e a responsabilidade pela aprendizagem (accountability).

Responsabilidade pela aprendizagem diz respeito à responsabilidade que cada pessoa tem pelas suas atitudes e consequências, bem assim pela aprendizagem a partir dessas consequências. Neste sentido, a responsabilidade pela aprendizagem trata de possuir a capacidade de aprender as lições contidas nas experiências profissionais vivenciadas, dos erros e acertos cometidos, refletindo a partir dos êxitos e dos fracassos. Já a informação válida é um valor que tem o propósito de orientar o comportamento dos indivíduos para não distorcer ou fabricar informações com vistas a se defender dos prováveis erros cometidos. Oferecendo fidedigno relato desses desacertos por meio de informações reais, a empresa pode se desenvolver através de um processo de revisão dos erros que porventura vierem a ocorrer. Para que a informação válida aconteça, outros dois valores são essenciais: transparência (transparency) e a orientação para o assunto (issue orientation). Transparência é a receptividade para feedbacks construtivos. É a coragem necessária de admitir lacunas, erros e deficiências sem se abater pelas sensações de autodecepção e desânimos que podem provocar a distorção de informações, gerando barreiras à aprendizagem. Sobre isso diz Souza-Silva (2007, p. 127) com base em Popper e Lipshitz (1988): “É a crença e concepção que devem existir numa cultura de aprendizagem capaz de influenciar as pessoas a dizer a elas próprias que todos podem cometer erros, e isso é um elemento normal e aceitável no processo de aprendizagem".

A orientação para a questão, por sua vez, enaltece o mérito dos argumentos, opiniões, afirmativas sobre uma determinada questão ou assunto independentemente de quem seja ou do status organizacional dos indivíduos que os defendem. Esta crença promove um ambiente de equalização de poder e intensifica a participação, as discordâncias, as polêmicas, potencializando a abertura dos canais de comunicação, trazendo progressos à aprendizagem e a inovação (POPPER; LIPSHITZ, 1998).

Além da investigação de Popper e Lipshitz (1998), há a pesquisa de Nevis, Dibella e Gould (1995), que também advogam que a cultura organizacional pode influenciar de forma significativa a aprendizagem. Nesse sentido, eles identificam dez fatores que favorecem a aprendizagem: imperativa varredura, intervalo de performance, preocupação com a mensuração, jogo experimental, clima de abertura, educação continuada, variedade operacional, múltiplos patronos, liderança envolvida, perspectiva sistêmica.

REAd | Porto Alegre - Vol. 23 - No Especial - Dezembro 2017 - p. 60-92 
A imperativa varredura (scanning imperative) trata de uma elevada conexão ao que acontece no contexto a qual a organização está inserida e opera. o intervalo de performance (performance gap) é a percepção da distância que separa os desempenhos atuais e ideais da empresa. Isso possibilita a organização compreender onde ela pode chegar e como ela pode evoluir.

A preocupação com a mensuração (concern for measurement) diz respeito à preocupação em medir a qualidade daquilo que é produzido pela empresa. Isso permite um fluxo de aprendizagem contínua. O jogo experimental (experimental mindset) sem refere a um espírito organizacional de sempre promover a experimentação. Ao experimentar continuamente, a empresa se arrisca, potencializa a aprendizagem, investiga soluções inovadoras e a organização ganha em aprendizagem.

Clima de abertura (climate of openess) diz respeito à crença de que as informações e o conhecimento devem circular de forma fluída, evitando as barreiras ao aprendizado e fomentando a partilha de experiência, o intercâmbio de significados através de um processo rico de troca e interação entre as pessoas. Educação continuada (continuos education) diz respeito ao compromisso com a educação e aprendizagem em todos os níveis da empresa. Variedade operacional (operational variety) trata-se das múltiplas possibilidades de se realizar os objetivos organizacionais. Essa flexibilidade potencializa a aprendizagem, pois as pessoas, na organização, refletem sobre distintas formas de conquistar os propósitos organizacionais, rompendo com os padrões mentais já cristalizados. múltiplos patronos (multiples advocates) diz respeito a uma crença existente na organização de que todos os indivíduos são responsáveis pela criação e multiplicação de informações, ideias e aprendizagem organizacional.

A liderança envolvida (involved leadership) é quando os gestores organizacionais estão engajados no processo de promoção da aprendizagem organizacional. Finalmente, a perspectiva sistêmica (systems perspective) é a habilidade de pensar e agir de forma ampla, evitando as visões reducionistas e fragmentadas e percebendo a interdependência das muitas variáveis organizacionais.

Outro pesquisador que enfatiza o relacionamento entre cultura e aprendizagem organizacional é Salaman (2001). Para ele, a cultura organizacional pode agir como poderosa potencializadora ou inibidora para que a aprendizagem aconteça. Para Salaman (2001), há potenciais barreiras à aprendizagem organizacionais, intimamente ligadas à questão da cultura organizacional, subdivididas em dois sistemas: normativo e cognitivo.

REAd | Porto Alegre - Vol. 23 - No Especial - Dezembro 2017 - p. 60-92 
Os componentes normativos da cultura influenciam a aprendizagem na medida em que eles fornecem normas e valores que definem como as pessoas relacionam-se umas com as outras e, em especial, sua disposição para mutuamente desafiarem-se, analisarem e refletirem coletivamente sobre determinados problemas. No que tange ao sistema cognitivo, Salaman (2001) argumenta que estruturas cognitivas partilhadas modelam as formas de pensar, construindo princípios que passam a ser encarados como verdadeiros. Nesse sentido, compreensão e significado partilhado geram um processo de construção da realidade que possibilita que as pessoas percebam e entendam determinados eventos ou situações de forma mais ou menos homogênea. A implicação desse raciocínio é de que esses sistemas cognitivos - enquanto aspectos da cultura organizacional - podem levar a rotinas contrárias à potencialização da aprendizagem organizacional, da inovação e da mudança. Por exemplo, boa parte das organizações possui em seus sistemas cognitivos a ideia de que a aprendizagem ocorre através da transferência de conhecimento explícito baseado eminentemente em mecanismos tradicionais como o treinamento. Assim, limita-se o potencial da aprendizagem uma vez que se preterem outros dispositivos como aqueles ligados à aprendizagem em contextos sociopráticos e laborais.

Wang e Ahmed (2003) também contribuem com o debate, dizendo que a cultura organizacional pode potencializar ou inibir a aprendizagem organizacional. Eles sinalizam que culturas marcadas por tradicionais estruturas hierárquicas minam a habilidade de as organizações sobreviverem e se adequarem ao ambiente de competição do mercado global (JONES, 1996). Tais autores ainda advogam que, somente inseridas numa cultura apropriada, as pessoas são capazes de contribuir com o processo de aprendizagem organizacional.

Nessa mesma linha, Tolbert (1991), a partir da noção de cultura libertadora, advoga que a cultura organizacional pode representar um meio de superar os obstáculos que limitam a aprendizagem. Bierly, Kessler e Christensen (2000) também contribuem com a discussão entre cultura e aprendizagem. Para eles, uma cultura organizacional apropriada pode possibilitar uma melhor utilização da experiência e do conhecimento nas organizações.

Egan, Yang e Bartlett (2004) são outros pesquisadores que se concentram na análise da cultura organizacional de aprendizagem. Tais autores focam seus trabalhos demonstrando o impacto da cultura organizacional de aprendizagem e da satisfação laboral na motivação para a transferência de aprendizagem e intenção de turnover.

O trabalho de Souza-Silva (2007) também demonstra como a cultura organizacional pode influenciar o processo de aprendizagem. Ao estudar uma importante modalidade de REAd | Porto Alegre - Vol. 23 - No Especial - Dezembro 2017 - p. 60-92 
aprendizagem socioprática - a comunidade de prática - tal pesquisador advoga que nem todas as organizações possuem ambientes propícios ao surgimento e desenvolvimento de tal modalidade de aprendizagem. Neste sentido, ele demonstra que um tipo especial de cultura denominada de Cultura Organizacional de Aprendizagem Socioprática acaba exercendo forte impacto para que as comunidades de prática possam emergir e se desenvolver. Segundo tal autor, a Cultura Organizacional de Aprendizagem Socioprática pode ser caracterizada pela existência de dois conjuntos de valores e crenças que agem simultaneamente, produzindo uma cultura organizacional especial: valorização da aprendizagem socioprática e valorização do elemento humano.

Embora esses autores assinalem a importância direta ou indireta de uma cultura de empresa imbuída de valores essenciais capazes de estimular a aprendizagem organizacional positiva, contributiva e benéfica, não são muitas as pesquisas que buscam se aprofundar no relacionamento entre cultura organizacional e mentoria foco da problemática desta pesquisa (LINDBO; SHULTZ, 1998).

Portanto, como foi visto, a mentoria é uma importante modalidade de aprendizagem organizacional, explorar empiricamente o relacionamento entre cultura organizacional de aprendizagem e mentoria pode representar uma interessante forma de se aprofundar nas raízes e razões de seu desenvolvimento, questão essa ainda pouco explorada pela literatura sobre o assunto. Além disso, compreender melhor os fatores que contribuem para os processos de aprendizagem nas organizações é estratégico num momento em que o conhecimento ganha centralidade para o sucesso num ambiente cada vez mais competitivo.

\section{MÉTODO}

A abordagem desta pesquisa é de cunho qualitativo, pois optou-se por utilizar o Estudo de Caso Simples e o Discurso do Sujeito Coletivo como estratégias metodológicas. O Discurso do Sujeito Coletivo (DSC) é uma técnica que surge no Brasil, no final da década de 1990, por iniciativa de dois pesquisadores da Universidade de São Paulo: Fernando Lefèvre e Ana Maria Cavalcanti Lefèvre (PAIXÃO et al., 2013).

O DSC tem o intuito de identificar as representações coletivas de um determinado grupo de indivíduos e está baseado nos pressupostos da Teoria das Representações Sociais (JODELET, 1989). O método tem natureza qualitativa, pois, se atém ao discurso (pensamento, material falado), uma variável de qualificação (LEFEVRE; LEFEVRE, 2012).

REAd | Porto Alegre - Vol. 23 - No Especial - Dezembro 2017 - p. 60-92 
O intuito do DSC é, justamente, unir as ideias comuns nos discursos dos entrevistados para identificar a sua representatividade social e coletiva. Gondim e Fischer (2009, p. 22) afirmam que "o DSC se atém à identificação dos sentidos e busca circunscrevê-los na teoria das representações sociais". Para se entender a técnica do DSC, é importante explicar três de seus elementos essenciais: (1) Expressões-Chaves (ECh); (2) Ideias Centrais (ICs); e (3) Discurso do Sujeito Coletivo (DSC). As Expressões Chaves (ECh) são trechos do discurso dos entrevistados que são destacados pelo pesquisador e que revelam a essência do conteúdo. A Ideia Central (IC) é a descrição, de maneira sintética e mais precisa possível, do sentido presente em cada resposta analisada, ou seja, em cada conjunto de ECh. A Ideia Central tem caráter discriminatório ou classificatório, possibilitando identificar e posicionar os depoimentos em um conjunto semântico equivalente.

Além do DSC, optou-se pelo estudo de caso, pois ele representa uma estratégia metodológica indicada para questões de pesquisa focadas no "como", bem assim para fenômenos contemporâneos e não completamente estudados (LEONARD-BARTON, 1990; YIN, 2010). O estudo de caso da presente investigação caracterizou-se como simples, pois foi utilizada a empresa de consultoria e auditoria denominada Performance como unidade de análise empírica. Através de um estudo preliminar baseado em critérios (apresentados no próximo tópico) constatou-se que tal empresa possuía práticas sólidas de mentoria, tornandose um interessante lócus de estudo para investigar o relacionamento entre o fenômeno da mentoria e a cultura organizacional.

\subsection{ESCOLHA DA UNIDADE DE ANÁLISE}

Com o intuito de identificar a unidade empírica de análise, foram estabelecidos alguns critérios para que o objetivo dessa investigação pudesse ser alcançado. Dessa forma, a organização deveria contemplar os seguintes critérios: (1) possuir um programa de mentoria (formal ou informal) dentro das características mínimas daquilo descrito pelo referencial teórico; (2) ser uma empresa com mais de 150 profissionais; (3) possuir tempo de mercado superior a dez anos; e (4) ter atuação nacional, possuindo sede em mais de um estado brasileiro. A primeira característica foi o critério essencial, pois se isso não ocorresse não seria possível levar a cabo o propósito dessa investigação que é investigar o fenômeno da mentoria e sua relação com cultura organizacional. As demais características foram relevantes, pois dão indícios de que a organização pesquisada possuía estrutura, rotinas e REAd | Porto Alegre - Vol. 23 - No Especial - Dezembro 2017 - p. 60-92 
procedimentos organizacionais mais consolidados e maduros representando, dessa forma, uma interessante unidade de análise para se estudar o processo de mentoria.

Inicialmente, foi identificado o segmento de empresas de consultoria e auditoria, pois é um setor no qual é imprescindível o processo de formação e aprendizagem de consultores e auditores, sobretudo, dos mais jovens para que eles aprendam determinados conhecimentos e habilidades relevantes para o exercício competente de suas atividades altamente especializadas. Algumas empresas desse ramo foram contatadas na região nordeste do Brasil. A escolhida foi a Performance: Auditoria e Consultoria, por atender aos critérios da pesquisa e por estar localizada na mesma cidade onde residem os autores desta investigação.

A Performance foi fundada, em Salvador (Bahia), no ano de 1990, por ex-executivos de empresas de auditoria e consultoria internacionais. Desde 2001, possui escritórios na Bahia, em São Paulo e no Rio de Janeiro. Iniciou sua atuação em consultoria tributária. Logo em seguida, como consequência do seu rápido crescimento, passou a prestar serviços em outras áreas. Atualmente, são oferecidas soluções nas áreas de auditoria e asseguração, consultoria financeira e empresarial, consultoria organizacional e capital humano, consultoria societária e tributária, consultoria trabalhista e previdenciária, e outsourcing. A empresa mantém centros de treinamentos onde são realizados programas de integração e desenvolvimento de suas equipes de trabalho, formadas por cerca de 160 colaboradores. A empresa consegue ter a maioria dos seus sócios com as suas carreiras profissionais desenvolvidas na própria organização (PERFORMANCE, 2012).

Através de orientações dos seus profissionais experientes, a Perfomance estimula o desenvolvimento dos novos consultores e auditores, capacitando-os a serem profissionais capazes de lidar com as mais diversas e complexas situações de negócios (PERFORMANCE, 2012).

\subsection{PRELIMINARES DO ESTUDO EMPÍRICO E A ESCOLHA DOS ENTREVISTADOS}

Em relação à escolha dos entrevistados, Lefevre e Lefevre (2012) advogam que na estratégia do DSC é importante que a amostra demonstre o espectro das diferentes opiniões sobre o assunto. Assim, para esta pesquisa, foram entrevistados doze profissionais com diferentes tempos de empresa e de atividade profissional, bem como de distintos níveis hierárquicos. Dessa forma, quatro pessoas encontravam-se no início de sua carreira, com o cargo de auditor júnior, quatro em uma posição intermediária, com o cargo de auditor pleno, e REAd | Porto Alegre - Vol. 23 - No Especial - Dezembro 2017 - p. 60-92 
quatro em uma posição mais avançada, com o cargo de auditor sênior. Essa divisão veio determinar o que Lefevre e Lefevre (2012) denominaram de amplitude da ideia, ou seja, o quanto uma ideia está disseminada no contexto pesquisado. Assim, pode-se identificar em que grupo de pessoas as representações sociais existem através de diferentes combinações. Todos entrevistados representavam protégés.

\subsection{ENTREVISTAS ESTRUTURADAS}

Para Lefevre e Lefevre (2012), as perguntas abertas sobre um tema e seus aprofundamentos e desdobramentos dirigidas a indivíduos entrevistados isoladamente, é o modo mais adequado de se obter depoimentos que possam conformar o pensamento de uma coletividade. Yin (2010) assevera que as entrevistas são uma das fontes mais importantes para estudo de caso. O autor afirma que duas tarefas são fundamentais no processo de entrevista: seguir a própria linha de investigação, conforme protocolo do estudo e formular questões de maneira imparcial, para que sejam úteis ao interesse do trabalho. Assim, dos profissionais entrevistados, teve-se, em média, uma hora de entrevista com cada um.

O protocolo de entrevista dividiu-se em duas partes. Na primeira parte, as perguntas serviram para caracterizar os tipos de mentoria existente na empresa investigada. A segunda parte referiu-se às perguntas sobre como a cultura organizacional influencia o processo de mentoria na Performance. Em outras palavras, a segunda parte, tratou de investigar a questão essencial dessa pesquisa a partir das representações sociais dos indivíduos na organização.

\section{RESULTADOS}

\subsection{CARACTERIZAÇÃO DA MENTORIA NA PERFORMANCE}

Tratou-se, a seguir, de caracterizar os tipos de mentoria existentes na Performance baseados nos principais tipos estabelecidos no referencial teórico. Essa caracterização foi feita através das respostas diretas dos entrevistados. Dessa forma, a porcentagem identificada para cada tipo de mentoria deu-se a partir da relação do número total de entrevistados pelo número de mentorias assinaladas pelos respondentes. Em relação à rede de relacionamentos, por exemplo, identificou-se o percentual de $50 \%$ da mentoria tradicional, significando que metade dos respondentes possui este tipo de relação de mentoria, não excluindo outros tipos de REAd | Porto Alegre - Vol. 23 - No Especial - Dezembro 2017 - p. 60-92 
relação para o mesmo respondente.

Assim, em relação à rede de relacionamentos, parte dos entrevistados (50\%) tem relações de mentoria caracterizadas como tradicionais (HIGGINS; KRAM, 2001; DOBROW et al.,2012), isto é, os protégés possuem 1 (no máximo 2) mentor(es) e mantém um relacionamento muito forte com ele(s). Outra parte dos entrevistados (37,5\%) tem vários mentores na Performance, mantendo relacionamento forte com eles. Como foi visto, anteriormente, esse tipo de mentoria é caracterizado como empreendedora (HIGGINS; KRAM, 2001; DOBROW et al.,2012). Esse tipo de relacionamento em rede é de grande valor para o aprendizado do protégé, pois o permite ter acesso a diferentes fontes de informações de forma contínua e intensa. Apenas um entrevistado (12,5\%) se enquadra na tipologia receptivo, uma vez que ele tem relações muito fracas com os seus poucos mentores. Esse entrevistado relata que tem acesso fácil para se comunicar com eles, pedindo ajuda e suporte sempre que necessário, mas os contatos são de forma não continuada e com um espaço de tempo muito longo em relação aos outros entrevistados. Nenhum tipo de relacionamento oportunista foi encontrado na organização investigada.

Em relação à formalização, os depoimentos mostraram que a organização não tem nenhum tipo de programa formal de mentoria. Todo o processo se desenvolve de forma espontânea, caracterizando todas as mentorias como informais (ENSHER; MURPHY, 2011).

Já em relação à hierarquia, na Performance, todos os entrevistados (100\%) possuem um relacionamento tradicional de mentoria, ou seja, o mentor está a um nível hierárquico bem acima do protégé. Somente um entrevistado (12,5\%) entende um dos seus colegas de trabalho também como um mentor, caracterizando assim uma relação de peer mentoring (PARKER; HALL; KRAM, 2008)

Finalmente, em relação ao contexto, na Performance, todas as mentorias (100\%), hoje, são presenciais, ou seja, tradicionais (HAMILTON; SACANDURA, 2003). Os meios eletrônicos são acessórios ao relacionamento de mentoria e não primordiais. Apenas um entrevistado (E5) disse que, no início do seu relacionamento, a mentoria tinha características de virtual, pois o seu mentor estava em outro Estado do Brasil e eles se comunicavam primordialmente por e-mails e telefonemas.

\subsection{A CULTURA ORGANIZACIONAL DE APRENDIZAGEM NA PERFORMANCE}

Para se entender como a cultura organizacional influencia no processo de mentoria da REAd | Porto Alegre - Vol. 23 - No Especial - Dezembro 2017 - p. 60-92 
Performance, faz-se necessário compreender quais valores estão contidos nessa cultura e suas consequências. Schein (1990) indica que os valores podem ser identificados através de entrevistas, pois demonstram como as pessoas falam e pensam sobre diferentes aspectos. Por conseguinte, utilizou-se o DSC para identificar esses valores contidos nos discursos dos entrevistados da organização.

Primeiramente, os dados foram modelados de acordo com as orientações de Lefevre e Lefevre (2012) que tratam de explicar o modo de se construir o Discurso do Sujeito Coletivo (DSC). Para cada indivíduo, foram identificadas as Ideias Centrais (ICs) e, por último, ordenaram-se as Expressões Chaves (EChs) recorrentes e os Discursos do Sujeito Coletivo (DSC) de todos os entrevistados.

Baseado em Hatch (1993), pode-se dizer que a manifestação é qualquer processo cuja essência da cultura se revela. Para a autora, as manifestações contribuem para o reconhecimento da cultura organizacional, traduzindo pressupostos intangíveis em valores reconhecíveis. No caso específico deste trabalho, os discursos são as manifestações para a revelação dos valores da organização. Em outras palavras, o DSC é a coletivização da manifestação dos valores culturais na empresa. Assim, através da análise criteriosa dos discursos individuais, extraiu-se a ideia central (IC) de diferentes valores e a sua importância no surgimento e desenvolvimento da mentoria. Assim, a tabela 1 a seguir, demonstra os valores encontrados nos discursos dos entrevistados.

Tabela 1 - Frequência dos ICs - Valores da cultura organizacional de aprendizagem que fomentam a mentoria

\begin{tabular}{|c|c|c|c|c|}
\hline $\begin{array}{l}\text { Dimensão } \\
\text { de Análise }\end{array}$ & $\begin{array}{c}\text { Ideia Central } \\
\text { (IC) }\end{array}$ & Valores da Cultura & $\begin{array}{c}\text { Frequência } \\
\text { Absoluta }\end{array}$ & $\begin{array}{c}\text { Frequência } \\
\text { Relativa }\end{array}$ \\
\hline \multirow{8}{*}{ 预 } & IC-A & Aprendizagem Continuada & 8 & $20,00 \%$ \\
\hline & IC-B & Orientação Humanista & 8 & $20,00 \%$ \\
\hline & IC-C & Disponibilidade para Interagir e Ajudar & 8 & $20,00 \%$ \\
\hline & IC-D & Busca pelo Progresso Profissional & 6 & $15,00 \%$ \\
\hline & IC-E & Autonomia Profissional & 4 & $10,00 \%$ \\
\hline & IC-F & Parceria & 3 & $7,50 \%$ \\
\hline & IC-G & Reconhecimento & 3 & $7,50 \%$ \\
\hline & & Total & 40 & $100,00 \%$ \\
\hline
\end{tabular}

Fonte: elaborado pelos autores.

No DSC demonstrado no Quadro 2 (IC-A), nota-se o quanto é importante o aprendizado continuado na empresa. A fala dos entrevistados descreve que a Performance não só incentiva os estudos, oferecendo suporte técnico e financeiro, mas, também, enaltece a aprendizagem que representa, inclusive, um ponto significativo na avaliação dos líderes e do 
RH na progressão de carreira do colaborador. Dessa forma, a Performance evidencia o aprendizado como algo fundamental que vai além dos treinamentos formais, contemplando a interação diária entre profissionais com a finalidade de partilhar experiências e conhecimentos como parte importante da dinâmica de aprendizagem na empresa.

Essa ideia central é um valor da cultura organizacional da Performance que se assemelha à noção de Aprendizagem Contínua apregoada por Popper e Lipshitz (1998), quando advogam sobre os cinco valores essenciais à uma cultura organizacional apropriada à aprendizagem. Além disso, esse valor da cultura da Performance, também, encontra profunda relação com a ideia de Educação Continuada de Nevis, Dibella e Gould (1995).

Porquanto, a partir do DSC do Quadro 2, esse contexto de aprendizagem continuada pode exercer uma grande influência no processo de mentoria. Seguindo a noção de que a mentoria é um processo eminentemente de aprendizado (LANKAU; SCANDURA, 2002), a busca de um profissional que ofereça o suporte profissional necessário para se obter conhecimento e crescimento na carreira, acaba se tornando algo natural e espontâneo nessa organização. A procura pelo aprimoramento através dos conhecimentos técnicos e práticos de uma pessoa mais experiente acaba por estimular os profissionais menos experientes a se juntarem a outros profissionais com características de um mentor.

Quadro 2 - Ideia Central: Aprendizagem Continuada (IC-A)

Discurso do Sujeito Coletivo (DSC) - O que favorece, aqui, é o fato de a Performance ser uma empresa de consultoria, que, por si só, já é um ambiente que necessita de aprendizado constante. Essa cultura de aprendizagem demanda atualização e estudo e meu líder nos direciona para isso. A Performance tem muito disso. A sua progressão profissional depende da sua avaliação semestral, e você, aqui, é avaliado também pelo seu gestor e pelo RH, por seu aprendizado. A empresa disponibiliza o horário, programações de treinamento. Além disso, a empresa incentiva os estudos pagando 50\%, a partir da função de consultor para você fazer uma pós-graduação, um curso de inglês, ou outra graduação. Eu vejo que a Performance também dá importância aos grupos de estudo. Muitas pessoas que já estão há um tempo na empresa passam vivências para nós, além das atualizações técnicas. O grupo de estudo é muito interessante. É de quinze em quinze dias no horário do expediente. Cada área faz o seu, mas a gente também pode participar de outros, e aí pode ser uma semana trabalhista, a outra tributária e assim sucessivamente. As pessoas se preocupam em passar o conhecimento, universalizar o conhecimento. E a empresa é magnífica nisso, porque ela te dá todas as possibilidades de você passar e receber conhecimento. Além dos treinamentos pré-estabelecidos, existe o treinamento diário. Como você trabalha em equipe, muitas vezes, tem um encarregado que tem uma experiência maior, tem os assistentes que têm uma experiência menor, e assim a gente vai para diretor, gerente, encarregado e assistente. Sempre que você chega à empresa, uma pessoa que é mais experiente está te passando as coisas.

Fonte: elaborado pelos autores.

O DSC descrito no Quadro 3 (IC-B) denota o sentimento comum de que a empresa se preocupa com o bem-estar do profissional. Essa percepção de que a empresa possui uma orientação humanista coloca o interesse comum acima dos interesses dos sócios da empresa. Isso não quer dizer que não haja problemas internos, conflitos e descontentamentos, mas a REAd | Porto Alegre - Vol. 23 - No Especial - Dezembro 2017 - p. 60-92 
noção de que o profissional é importante para a empresa e que ela se importa de forma honesta com as demandas, necessidades e anseios de seus funcionários.

Quadro 3 - Ideia Central: Orientação Humanista (IC-B)

Discurso do Sujeito Coletivo (DSC) - Eu percebo, aqui, um clima acolhedor. Eu vejo isso na figura do Sr. Mendonça (o fundador). Ele trata aqui como se fosse uma família, e isso é passado para gente. Não existe a preocupação só com o trabalho, e sim com a gente. Tem toda uma preocupação de como a gente vai para o cliente, de quantas horas a gente vai conseguir fazer, realizar um bom trabalho. Outra empresa talvez não fizesse isso. Cobrasse apenas. A pessoa tira o seu tempo para conversar, almoçar junto entre outras coisas. Tem empresa que só foca no trabalho, não está muito preocupada como o outro está, se ele vai crescer. Há empresas que se preocupam mais no resultado e nos lucros. Então, eu acho que esse ambiente da Performance, de ser flexível, de ter um ambiente de amizade, de ter esse valor é importante. É uma empresa que não só se preocupa com a imagem dela, ela se preocupa com o profissional, o colaborador. Eu vejo que, em outras empresas, a visão do negócio é estritamente profissional. Você se sente como uma ferramenta, você se sente usado para fazer aquele determinado trabalho. Aqui, eu acho diferente.

Fonte: elaborado pelos autores.

A ideia central em questão realça um valor na cultura da Performance ainda não assinalado na literatura sobre o assunto. É inegável, no entanto, que o sentimento de que a organização possui uma orientação humanista promove um ambiente mais intimista e mais amistoso. Dessa forma, o profissional se sente mais confortável em procurar alguém mais experiente para falar dos seus problemas, pedir ajuda, solicitar conselhos e criar vínculos afetivos e profissionais, catalisando o surgimento e desenvolvimento de processos de mentoria organizacional.

O DSC da IC-C, apresentado no Quadro 4, trata do valor Disponibilidade para Interagir e Ajudar. Constata-se, a partir da fala dos entrevistados, que as pessoas, na Performance, estão sempre disponíveis para ajudar umas às outras. Esse valor indica que, facilmente, os funcionários menos experientes terão acesso a profissionais mais experientes quando necessitarem de ajuda e essa disponibilidade é fundamental para que se possam criar relacionamentos com possíveis mentores dentro da organização.

Quadro 4 - Ideia Central: Disponibilidade para Interagir e Ajudar (IC-C)

Discurso do Sujeito Coletivo (DSC) - Muita gente sai daqui e se decepciona, pois as pessoas não estão disponíveis para ajudar e interagir com o outro em muitas outras empresas lá fora. Porque lá o pessoal não é amigável, não é receptivo, são pessoas frias. Eu acho que existe uma interação entre os setores na Performance, um compartilhamento de conhecimento entre esses setores. A maioria não se importa em te ajudar e conversar com você. O que favorece é o contato que a gente tem com os gerentes e diretores que são bem abertos. Independente do volume de trabalho, eles estão sempre disponíveis para ajudar. Indo de cima para baixo, de baixo para cima, existe disponibilidade para ajudar. Quando há necessidade de ajuda, você sempre encontra pessoas disponíveis. E, no nosso trabalho, isso é muito importante, porque você está sempre em contato com coisas novas. Então, você ficaria perdido em algumas situações se não tivesse essa disponibilidade das pessoas para te orientar.

Fonte: elaborado pelos autores.

REAd | Porto Alegre - Vol. 23 - No Especial - Dezembro 2017 - p. 60-92 
A ideia central Disponibilidade para Interagir e Ajudar traz alguma semelhança com a noção de Clima de Abertura proposta por Nevis, Dibella e Gould (1995). Quando há espaço para as pessoas se ajudarem mutuamente, há espaço também para um maior entrosamento entre diferentes profissionais, criando um clima de abertura para que eles possam procurar um suporte para tirar dúvidas sobre o trabalho e a profissão, ou mesmo para falar dos seus sentimentos em relação a determinado assunto, criando um ambiente propício ao aprendizado e ao desenvolvimento da mentoria.

O DSC do Quadro 5 (IC-D) revela que o progresso profissional é buscado pelos funcionários da Performance. O plano de carreira é muito transparente na organização e mostra onde o profissional está e aonde pode chegar nesta empresa. Todos sabem para onde se está indo e quais são os parâmetros da sua avaliação. Essa avaliação é semestral e traça planos específicos para o empregado se desenvolver na organização. Esses feedbacks na organização são entendidos como uma forma de se melhorar e se aperfeiçoar na sua carreira. Dessa forma, o profissional se sente motivado a progredir. Quando há esse valor na cultura organizacional, pressupõe-se que o funcionário seja induzido a firmar objetivos de ascensão profissional. Isso o fará procurar e manter um mentor. A Busca pelo Progresso Profissional assemelha-se à noção de Intervalo de Performance (NEVIS; DIBELLA; GOULD, 1995) com uma diferença. Na primeira, a perspectiva é individual; na segunda, como visto no referencial téorico é organizacional. No entanto, as duas guardam a ideia de evolução e progresso, pois um contexto de aprendizado é pautado por reflexões de situações atuais e ideais tanto sob a perspectiva individual quando organizacional. Perceber a distância que separa uma situação presente de uma futura mais desenvolvida cria uma tensão criativa que pode induzir ações, comportamentos e atitudes de aprendizagens, inclusive fomentando processos de mentoria como ocorre no caso da Performance através do valor Busca pelo Progresso Profissional.

Quadro 5 - Ideia Central: Busca pelo Progresso Profissional (IC-D)

Discurso do Sujeito Coletivo (DSC) - Eu acho que um plano de carreira é fundamental, porque se a pessoa tem um foco, ela sabe que para chegar a esse foco, precisa desenvolver todo um perfil para chegar lá. Você vai treinando devagarzinho, até alcançar seu objetivo. E, se você tiver um bom desempenho, você vai ser promovido, pois é a política da Performance. Saber que eu posso progredir na minha carreira me faz sentir valorizada. Todo ano tem uma avaliação onde há um feedback de todo o seu trabalho. A pessoa fica motivada com a sua avaliação. Então, você vai sempre tentar melhorar, cada dia mais. Tem lá na intranet um programa. As pessoas entram e visualizam como podem se movimentar dentro da carreira, até onde podem chegar. $\mathrm{O}$ plano de carreira oferecido pela empresa descreve a parte prática da evolução. Você sente na prática a evolução. Você mensura a sua evolução. A gente realmente observa o discurso e a prática se alinhando aqui.

Fonte: elaborado pelos autores.

REAd | Porto Alegre - Vol. 23 - No Especial - Dezembro 2017 - p. 60-92 
O DSC do Quadro 6 discorre sobre a IC-E que diz respeito ao valor Autonomia Profissional. Percebe-se o quanto o profissional se sente valorizado quando ele possui autonomia no seu trabalho. Verifica-se, a partir da fala dos entrevistados, que a Performance permite que os funcionários resolvam por eles próprios seus problemas e desafios profissionais. É através desses desafios propostos e do sentimento de responsabilidade que o profissional é induzido a procurar por apoio de alguém que possa orientá-lo e lhe dar suporte nas situações desafiantes e inusitadas, favorecendo o desenvolvimento de mentorias.

Quadro 6 - Ideia Central: Autonomia Profissional (IC-E)

Discurso do Sujeito Coletivo (DSC) - Quando você entra aqui, você recebe a chave da empresa no primeiro dia. Você é responsável pelo seu material, recebe o seu laptop, é você que tem que cuidar. Eu acho que é essa autonomia que a Performance oferece de me deixar resolver o problema é um importante valor. Há gerentes e líderes que centralizam, e só eles podem resolver. Meu gerente me dá espaço para resolver. Com a autonomia que tenho na empresa, sempre aparecem diferentes tipos de desafios. Estou sempre enfrentando situações diferentes e tentando resolver problemas novos com os quais eu nunca tinha me deparado antes. É sempre muito estimulante e desafiador o meu trabalho. No dia a dia, ocorrem os feedbacks pelos desafios que vão surgindo. Quando a gente dá uma autonomia para alguém, a gente entende que aquela pessoa tem condições de fazer aquilo que lhe está sendo oferecido. Então, eu acho que é mais ou menos assim. É igual ao esporte. Quando a gente cobra muito de um Neymar da vida, é porque sabe que ele tem condições de oferecer um desempenho de alto nível.

Fonte: elaborado pelos autores.

O valor Autonomia Profissional assemelha-se à ideia Responsabilidade pela Aprendizagem fruto do trabalho de Popper e Lipshitz (1998). Ao receber autonomia profissional, o protégé assume a responsabilidade pelo seu aprendizado não o delegando a outrem. Assumir a responsabilidade pela própria aprendizagem não significa que o protégé vai aprender sozinho, mas significa ser o estrategista do seu próprio desenvolvimento, inclusive elegendo mentores para adquirir conhecimentos e melhor orientá-lo na resolução de problemas e no suporte para trilhar os caminhos do sucesso profissional. Isso dinamiza o surgimento e a manutenção de processos de mentoria, intensificando a aprendizagem organizacional.

O Quadro 7 trata-se do discurso do sujeito coletivo da IC-F que diz respeito ao valor Parceria. Segundo os entrevistados, a parceria é o sentimento de que há um apoio e suporte mútuo entre as pessoas da organização mediada pela confiança que se tem um pelo outro. Numa cultura onde existe o valor da parceria, o profissional se sente mais confortável de trabalhar, pois percebe que todos estão comungando de um mesmo objetivo. As pessoas se sentem mais seguras e tendem a permanecer na empresa por mais tempo.

REAd | Porto Alegre - Vol. 23 - No Especial - Dezembro 2017 - p. 60-92 
Quadro 7 - Ideia Central: Parceria (IC-F)

Discurso do Sujeito Coletivo (DSC) - Hoje, a empresa confia em mim, confia no meu trabalho. Então, o relacionamento com as pessoas fica mais claro, fica mais transparente, as pessoas ficam muito mais próximas. Eu me sinto parceira da empresa e das pessoas com quem eu trabalho. Eu acho que eu tenho um relacionamento muito mais seguro, maduro com meu gerente, por exemplo. De confiança mesmo, de parceria. Eu acho que é importante a confiança que a Performance passa e que ela deposita em mim. Existe um relacionamento de confiança mútuo e isso se traduz no resultado da empresa como um todo. Tem que ter esse entrosamento entre as pessoas, onde cada um procura ajudar o outro e sente que não está sozinho. Eu acho que a confiança, a parceria, seria mais ou menos isso. Seria você não ser uma ferramenta, mas ser parceiro, sentindo-se parte do negócio. Como se fosse uma equipe mesmo de trabalho, todo mundo com o mesmo pensamento. Se você tem a parceria, confia no seu par.

Fonte: elaborado pelos autores.

Segundo os entrevistados, esse valor intensifica o entrosamento e fomenta um relacionamento de confiança, pois as pessoas se sentem mais seguras e confiantes na dinâmica de interação interpessoal. Por conseguinte, cria-se um ambiente propício para que a mentoria se estabeleça dentro da Performance. Dito de outra forma, quando há o sentimento de parceria, o profissional se sente muito confortável em manter relacionamentos com pessoas mais experientes na organização, pois ele confia que haverá sempre a intenção sincera de ajudá-lo. Isso melhora a qualidade e a efetividade do relacionamento entre o mentor e o protégé, pois o mentorado acredita que os conselhos e desafios proporcionados por seu mentor é para o seu melhor interesse. Assim, o protégé se sente muito mais confortável nas direções e feedbacks oferecidos a ele. Não se encontrou na literatura sobre o assunto, nenhum valor que se assemelha integralmente com este salientado na IC-F.

O DSC do Quadro 8 discorre sobre a IC-G que trata do valor Reconhecimento. Segundo os entrevistados, o reconhecimento é um valor que gera uma emoção positiva de gratidão e satisfação quando o seu trabalho e suas atitudes são vistos e apreciados de maneira honesta pela organização. Percebe-se, neste DSC, que o profissional não quer decepcionar a organização, como também deseja retribuir o que ele entende que está sendo oferecido para ele. Quando há o reconhecimento, o profissional se sente satisfeito e motivado a trabalhar da melhor maneira possível, pois percebe justiça por parte de seus pares. O reconhecimento tem reflexos diretos na relação da mentoria. Quando o profissional sente que pode ser reconhecido pelo seu trabalho e atitudes na organização, ele procura desenvolver um melhor trabalho a cada momento. Nesse sentido, a procura e a manutenção de alguém, mais experiente, que possa dar conselhos e dividir experiências, se tornam fundamentais. Os entrevistados sugerem que o valor Reconhecimento promove um elevado sentimento de satisfação laboral. Assim, pode-se depreender que este valor se aproxima muito dos achados de Egan, Yang e Bartlett 
(2004) que enfatizam a relevância da satisfação laboral como elemento que impulsiona a intenção em transferir conhecimentos e promover a aprendizagem na organização.

Quadro 8 - Ideia Central: Reconhecimento (IC-G)

\begin{abstract}
Discurso do Sujeito Coletivo (DSC) - Quando você faz um bom trabalho e recebe um elogio é gratificante. $\mathrm{Eu}$ acho que você quer fazer um trabalho ainda melhor, você veste a camisa da empresa. Esse reconhecimento que a empresa me dá faz com que, a cada dia mais, eu busque, eu me esforce mais para poder cumprir o meu trabalho. Para poder agradar. Eu sei que a empresa tem expectativa. Então, eu não gosto de voltar com uma pendência não resolvida. Não posso decepcionar. Quando você se sente valorizado, você sente que tem que oferecer mais para a empresa. Retribuir aquilo que você está sentindo. Então, você se sente motivado, você quer contribuir mais. Eu me sinto muito reconhecido pelo meu trabalho, aqui. Há sempre feedbacks, sejam positivos ou negativos. Quando você erra ou necessita melhorar em algum ponto, isso é dito diretamente para você, mas você sente que é para o seu melhor interesse. Já, quando o seu trabalho é bem feito, sempre existe o reconhecimento por parte da empresa e do seu líder. As pessoas são reconhecidas publicamente aqui na Performance, e meu trabalho é evidenciado não só no meu setor como em toda a empresa. Eu me sinto muito satisfeito em trabalhar aqui na Performance.
\end{abstract}

Fonte: elaborado pelos autores.

Constata-se que os valores salientados pelos entrevistados (Aprendizagem Continuada, Disponibilidade para Interagir e Ajudar, Busca pelo Progresso Profissional, Autonomia Profissional e Reconhecimento) possuem semelhanças com os valores de uma cultura organizacional de aprendizagem discutidos no referencial teórico (POPER; LIPSHITZ, 1998; NEVIS; DIBELLA; GOULD, 1995; EGAN; YANG; BARTLETT, 2004). Os valores Orientação Humanista e Parceria não trazem semelhança com nenhum outro valor assinalado pela literatura.

\title{
3.3 CATEGORIZAÇÃO DOS VALORES DA CULTURA ORGANIZACIONAL DE APRENDIZAGEM NA PERFORMANCE
}

A partir da fala dos entrevistados, os DSC apresentados sugerem que os valores presentes na cultura organizacional de aprendizagem da Performance exercem influência direta no surgimento e desenvolvimento de mentorias. Numa tentativa de melhor entender como a cultura influencia no processo de mentoria na Performance, resolveu-se realizar um exercício de categorização valores encontrados. Dessa forma, encontrou-se três categorias de valores que impactam no processo de mentoria da Performance. São eles, valores ligados à: valorização do desenvolvimento técnico-profissional, valorização da interação social e valorização do ser humano.

REAd | Porto Alegre - Vol. 23 - No Especial - Dezembro 2017 - p. 60-92 
Quadro 9 - Categorias dos valores que influenciam a mentoria na performance

\begin{tabular}{|c|c|}
\hline $\begin{array}{c}\text { Categoria de Valores da Cultura Organizacional de } \\
\text { Aprendizagem que influenciam no Processo de } \\
\text { Mentoria }\end{array}$ & Detalhamento dos Valores \\
\hline Valores ligados à Valorização do Desenvolvimento & $\begin{array}{c}\text { Aprendizagem Continuada, Busca pelo } \\
\text { progresso Profissional, Autonomia Profissional }\end{array}$ \\
\hline Valores ligados Valorização da Interação Social & $\begin{array}{c}\text { Disponibilidade para interagir e ajudar e } \\
\text { Parceria }\end{array}$ \\
\hline Valores ligados Valorização do Ser Humano & Orientação Humanista, Reconhecimento \\
\hline
\end{tabular}
Fonte: elaborado pelos autores.

A categoria de valorização do desenvolvimento técnico-profissional concentra os valores que são contributivos para o aperfeiçoamento profissional e desenvolvimento da carreira do protégé (aprendizagem continuada, busca pelo progresso profissional e autonomia professional). A aprendizagem continuada é um valor que provoca o interesse genuíno e permanente do protégé em aprender e melhorar o seu conhecimento. A busca pelo progresso profissional é o valor que impele o mentorando a seguir os objetivos de sua carreira, desenvolvendo-se, dessa forma, para alcançar os seus planos profissionais. A autonomia profissional é o valor que contribui para o profissional tomar iniciativa e responsabilizar-se por suas ações, procurando, assim, aperfeiçoar-se mais para fazer um bom trabalho continuamente. Esses três tipos de valores têm impacto direto no desenvolvimento técnicoprofissional do protégé e o estimulará a buscar um mentor que possa contribuir para seu crescimento profissional.

Na categoria de valorização da interação social, encontram-se os valores que fomentam a socialização e interação dos membros da organização e, por conseguinte, a relação pessoal do protégé e do seu mentor. A disponibilidade para interagir e ajudar é o valor que faz com que os indivíduos estejam sempre dispostos a oferecer ajuda no trabalho dos seus pares, seja qual for o nível hierárquico. Já a parceria permite que as interações na organização sejam concretizadas com mais segurança e confiança, permitindo relações mais sólidas e prolongadas. Assim, esses valores têm características sócio-interacionais preponderantes na cultura de aprendizagem da organização, tornando as relações mais intimistas entre os profissionais da organização, inclusive entre mentores e protégés, cultivando e nutrindo o surgimento e o desenvolvimento de mentorias.

Por último, a categoria de valorização do ser humano concentra aqueles valores que são importantes para que cada profissional tenha uma relação de compromisso e respeito com o ser humano na organização. A orientação humanista é o valor que afirma que o indivíduo é um fator fundamental para a organização e que ela se importa com cada profissional. $\mathrm{O}$ 
reconhecimento é o valor que gera uma emoção positiva de gratidão e satisfação quando o seu trabalho e suas atitudes são vistas e apreciadas de maneira honesta pelas pessoas na organização. Dessa forma, esses valores contribuem para que o protégé se sinta valorizado como indivíduo na empresa. A mentoria desenvolve-se em bases de sólida confiança entre o mentor e o protégé, pois eles entendem os seus papéis na organização. Além disso, tal conjunto de valores desenvolve a consciência e a responsabilidade que cada pessoa possui com o aprimoramento e o crescimento profissional e humano dos seus pares naquele ambiente organizacional, fomentando ainda mais o desenvolvimento do processo de mentoria.

\section{CONSIDERAÇÕES FINAIS}

Cook e Yanow (1993) afirmam que os profissionais e acadêmicos necessitam enxergar a organização não como uma entidade cognitiva, mas como uma entidade cultural para entender o seu processo de aprendizagem (GARCÍA-MORALES; LLORÉNS-MONTES; VERDÚ-JOVER, 2008). Características das organizações são reflexos da cultura dominante e suas subculturas. Assim, a análise cultural é fundamental para o entendimento mais holístico do aprendizado organizacional. Por meio deste estudo, procurou-se o aprofundamento na reflexão de como a cultura organizacional de aprendizagem influencia o processo de mentoria na empresa Performance. Dessa forma, chega-se à conclusão de que a cultura da organização estudada influencia, fortemente, a dinâmica da mentoria a partir de três categorias de valores ligados à valorização: do desenvolvimento técnico-profissional, da interação social e do ser humano.

Através dos resultados obtidos, algumas implicações podem ser propostas neste trabalho. A primeira é a constatação de que a cultura organizacional de aprendizagem na Performance funciona como um fator poderoso no favorecimento do desenvolvimento do processo de mentoria nesta empresa. Apesar de esta pesquisa ter sido baseada num estudo de caso simples e a validade ser interna, tais achados trazem reflexões e insights interessantes e capazes de incentivar outros debates com vistas a trazer novos avanços à teoria ligada tanto ao construto da cultura quanto da mentoria. Sendo assim, pode-se inferir que se uma organização deseja possuir um processo de mentoria mais desenvolvido, é interessante cultivar os valores influenciadores desse processo.

Outra implicação da pesquisa é realçar a mentoria como uma interessante via de aprendizagem organizacional marcadamente socioprática e interacionista como foi discutido REAd | Porto Alegre - Vol. 23 - No Especial - Dezembro 2017 - p. 60-92 
no referencial teórico (ALMEIDA; SOUZA-SILVA, 2015; DOS-SANTOS, et al., 2015). Neste sentido, a investigação permite refletir que a aprendizagem organizacional não deve se restringir apenas aos treinamentos tradicionais que têm sido duramente criticados por alguns autores por privilegiar apenas a parte explícita do conhecimento e, em grande medida, ser descontextualizado da prática laboral. Em outras palavras, a partilha de conhecimentos e experiências construídas no cotidiano do relacionamento da mentoria pode ser uma excelente fonte de aprendizagem organizacional e uma alternativa factível de promoção do intercâmbio de conhecimentos, experiências, vivências e expertises tão importantes para o aprimoramento individual e para o processo de competitividade empresarial.

\section{REFERÊNCIAS}

ALLEN, T. D.; EBY, L. T.; POTEET, M. L.; LENTZ, E.; LIMA, L. Career benefits associated with mentoring. Journal of Applied Psychology, Washington, v. 89, n. 1. p. 127136, 2004.

ALMEIDA, N. C. P.; SOUZA-SILVA, J. C. Aprendizagem organizacional e formação de gestores: como aprendem os gestores em uma indústria do setor petroquímico. Revista de Gestão, São Paulo v. 22, n. 3, p. 383-404, 2015.

ALVESSON, Mats; KÄRREMAN, Dan. Odd couple: making sense of the curious concept of knowledge management. Journal of Management Studies, Hoboken, v. 38, n. 7, p. 9951018, 2001.

ANTONACOPOULOU, E. P. Reconnecting education, development and training through learning: a holographic perspective. Education \& Training, Bingley, v. 42, n. 4-5, p. 255-263, 2000.

AZEVEDO, Débora. Tensões e extensões da aprendizagem organizacional - possíveis questões epistemológicas. In: ENCONTRO DA ASSOCIAÇÃO NACIONAL DE PÓS GRADUAÇÃO E PESQUISA EM ADMINISTRAÇÃO - ENANPAD, 37, 2012, Rio de Janeiro. Anais... Rio de Janeiro: ANPAD, 2012.

BERTOLIN, Rosangela Violetti; ZWICK, Elisa; BRITO, Mozar José de. Aprendizagem organizacional socioprática no serviço público: um estudo de caso interpretativo. Revista de Administração Pública, Rio de Janeiro, v. 47, n. 2, p. 493-513, Apr. 2013.

BIERLY, P. E.; KESSLER, E. H.; CHRISTENSEN, E. W. Organizational learning, knowledge and Wisdom. Journal of Organizational Change Management, Bingley, v. 13, REAd | Porto Alegre - Vol. 23 - No Especial - Dezembro 2017 - p. 60-92 
n. 6, p. 595-618, 2000.

BINGHAM, C. B.; DAVIS, J. P. Learning Sequences: Their Existence, Effect, and Evolution. Academy of Management Journal, Briarcliff Manor, v. 55, n. 3. p. 611-641, 2012. BOZERMAN, B.; FEENEY, M. K. Toward a useful theory of mentoring: a conceptual analysis and critique. Administration \& Society, Thousand Oaks, v. 39, n. 6, p. 719-739, 2007.

BROWN, J. S. e DUGUID, P. Knowledge and organization: a social-practice perspective. Organization Science, Catonsville, v. 12, n. 2, p. 198-213, 2001.

CHAO, G. T.; WALZ, P. M.; GARDNER, P. D. Formal and informal mentorships: a comparison on mentoring functions and contrast with nonmentored counterparts. Personnel Psychology, Medford, v. 45, n. 3, p. 619-636, 1992.

BRITO-DE-JESUS, K. C.; DOS-SANTOS, M.G.; SOUZA-SILVA, J.C.de; RIVERACASTRO, M. A. Desenvolvimento de competências gerenciais de gestores públicos em instituições federais de educação. Revista Interdisciplinar de Gestão Social (RIGS), Salvador, v. 5, n. 1 p. 37-60, Jan/Abr. 2016.

COOK, S. D. N.; BROWN, J. S. Bridging epistemologies: The generative dance between organizational knowledge and organizational knowing. Organizational Science, Catonsville, v. 10, n. 4, p. 381-400, 1999.

COOK, S. D. N.; YANOW, D. Culture and organizational learning. Journal of Management Inquiry, Thousand Oaks, v. 2, n. 4. p. 373-390, 1993.

DOBROW, S. R.; CHANDLER, D. E.; MURPHY, W. M., KRAM, K. E. A review of developmental networks. Journal of Management, Thousand Oaks, v. 38, n. 2, p. 210-242, Jan. 2012.

DONALDSON, S. I.; ENSHER, E. A.; GRANT-VALLONE, E. J. Longitudinal examination of mentoring relationship on organizational commitment and citizenship behavior. Journal of Career Development, Thousand Oaks, v. 26, n. 4, p. 233-249, 2000.

EGAN, T. M.; YANG, B.; BARTLETT, K. R. The effects of organizational learning culture and job satisfaction on motivation to transfer learning and turnover intention. Human Resource Development Quarterly, Medford, v. 15, n. 3, p. 279-301, 2004. ELLIS, S.; SPIELBERG, N. Organizational learning mechanisms and managers perceived uncertainty. Human Relations, Thousand Oaks, v. 56, n. 10, p. 1233-1254, 2003.

ENSHER, E. A.; HEUN, C. BLANCHARD, A. Online mentoring and computer-mediated communication: new directions in research. Journal of Vocational Behavior, Atlanta, v. 63, REAd | Porto Alegre - Vol. 23 - No Especial - Dezembro 2017 - p. 60-92 
n. 2, p. 264-288, 2003.

ENSHER, E. A.; MURPHY S. E. The mentoring relationship challenges scale: the impact of mentoring stage, type, and gender. Journal of Vocational Behavior, Atlanta, v. 79, n. 1, p. 253-266, 2011.

ENSHER, E. A.; THOMAS, C; MURPHY, S. E. Comparison of traditional, step-ahead, and peer mentoring on protégés' support, satisfaction, and perceptions of career success: a social exchange perspective. Journal of Business and Psychology, New York, v. 15, n. 3, p. 419438, 2001.

GARCÍA-MORALES, V. J.; LLORÉNS-MONTES, F. J.; VERDÚ-JOVER, A. J. The effects of transformational leadership on organizational performance through knowledge and innovation. British Journal of Management, Medford, v. 19, n.4, p. 299-319, 2008. GHERARDI, Silvia. How to conduct a practice-based study: problems and methods. Cheltenham, UK: Edward Elgar Publishing, 2013. 256p.

GHERARDI, S.; NICOLINI, D.; ODELLA, F. Toward a social understanding of how people learn in organizations. Management Learning, Thousand Oaks, v. 29, n. 3, p. 273-297, 1998.

GONDIM, S. M.; FISCHER, T. O discurso, a análise de discurso e a metodologia do discurso do sujeito coletivo na gestão Intercultural. Cadernos Gestão Social, Salvador, v. 2, n. 1, p. 09-26, 2009.

GUEIROS, M. M. B. Um estudo sobre a rede de relações de desenvolvimento profissional construídas pelos dirigentes em organização familiar. In: ENCONTRO DA ASSOCIAÇÃO NACIONAL DOS PROGRAMAS DE PÓS- GRADUAÇÃO EM ADMINISTRAÇÃO ENANPAD, 33, 2012. Anais... Rio de Janeiro: ANPAD, 2012.

GUTNER, T. Finding anchors in the storm: mentors. 2009. Disponível em: <https://www.wsj.com/articles/SB123301451869117603> Acesso em: 10 julho 2017. HAMILTON, B.A.; SCANDURA, T.A. E-mentoring: implications for organizational learning and development in a wired world. Organizational Dynamic, Atlanta, v. 31, n.4, p. 388-402, 2003.

HATCH, M. J. The dynamics of organizational culture. Academy of Management Review, Briarcliff Mano, v. 18, n. 4, p. 657-693, 1993.

HIGGINS, M.; KRAM, K. Reconceptualizing mentoring at work: a developmental network perspective. The Academy of Management Review, Briarcliff Mano, v. 26, n. 2, p. 264-288, 2001.

REAd | Porto Alegre - Vol. 23 - No Especial - Dezembro 2017 - p. 60-92 
ILLERIS, K. (Org.). Teorias contemporâneas da aprendizagem. Porto Alegre: Penso, 2013. 280p.

JOO, B; LIM, T. The effects of organizational learning culture, perceived job complexity, and proactive personality on organizational commitment and intrinsic motivation. Journal of Leadership \& Organizational Studies, Thousand Oaks, v. 16, n. 1. p. 48-60, Aug. 2009. JODELETE, D. Répresentations sociales: un domaine en expansion. JODELETE, D. (Org.). Répresentations sociales. Paris: PUF, 1989. p.31-61.

JONES, S. Developing a learning culture: empowering people to deliver quality, innovation and long-term success. New York: McGraw-Hill Book Company, 1996. 192p. KOFMAN, F.; SENGE, P. M. Communities of commitment: The heart of learning organizations. CHAWLA, S. e RENESCH, J. (Eds.). Learning Organizations: Developing Cultures for Tomorrow's Workplace. Oregon: Productivity Press, 1995. p. 1-18.

KRAM, K. E. Phases of the mentor relationship. Academy of Management Journal, Briarcliff Mano, v. 26, n. 4, p. 608-625, 1983.

KRAM, K. E.; RAGINS, B. R. The landscape of mentoring in the $21^{\text {st }}$ century. RAGINS, B. R.; KRAM, K. E. (Eds.). The handbook of mentoring at work: theory, research, and practice. Thousand Oaks, CA: Sage Publications, 2007. p. 659-687.

KRAM, K. E.; ISABELLA, L. Mentoring alternatives: The role of peer relationships in career development. Academy of Management Journal, Briarcliff Mano, v. 28, n. 1, p. 110-132, 1985.

LANKAU, M. J.; SCANDURA, T. A. An investigation of personal learning in mentoring relationship: content, antecedents, and consequences. Academy of Management Journal, Briarcliff Mano, v. 45, n. 4, p. 779-790, 2002.

LEFEVRE, F.; LEFEVRE, A. M. C. Pesquisa de representação social: um enfoque qualiquantitativo. 2. ed. Brasília: Liber Livros Editoras, 2012. 224p.

LEONARD-BARTON, D. A dual methodology for case studies: synergistic use of a longitudinal single site with replicated multiple sites. Organization Science, Catonsville, v.1, n.3, p. $248-266,1990$.

LESTER, P. B.; HANNAH, S. T.; HARMS, P. D.; VOGELGESANG, G. R.; AVOLIO, B. J. Mentoring impact on leader efficacy development: A field experiment. Academy of Management Learning \& Education, Briarcliff Mano, v. 10, n. 3, p. 409-429, 2011. LINDBO, T. L.; SHULTZ, K. S. The role of organizational culture and mentoring in mature worker socialization toward retirement. Public Productivity \& Management Review, REAd | Porto Alegre - Vol. 23 - No Especial - Dezembro 2017 - p. 60-92 
Oxfordshire, v. 22, n. 1, p. 49-59, Sep. 1998.

MERTZ, N.T. What's a mentor, anyway? Educational Administration Quarterly, Thousand Oaks, v. 40, n. 4, p. 541-560, 2004.

NEVIS, Edwin C.; DIABELLA, Anthony J.; GOULD, Janet M. Understanding organizations as learning systems. Sloan Management Review, Cambridge, v. 36, n. 2, p. 73-85, 1995. NICOLINI, D.; GHERARDI, S.; YANOW, D. Toward a practice-based view of knowing and learning in organization. NICOLINI, D.; GHERARDI, S.; YANOW, D. (Eds.) Knowing in organizing: A practice-based approach. New York: M. E. Sharper, 2005. p. 3-31. PAIXÃO, R. B.; MELO, D. R. A. de; SOUZA-SILVA, J. C de; CERQUINHO, K. G. Por que ocorre? Como lidar? A percepção de professores de graduação em Administração sobre o assédio moral. Revista de Administração, São Paulo, v. 48, n. 3, p. 516-529, 2013.

PARKER, P.; HALL, D.T.; KRAM, K.E. Peer coaching: A relational process for accelerating career learning. Academy of Management Learning \& Education, Briarcliff Manor, v.7, n. 4, p. 487-503, 2008.

PERFORMANCE. Sobre a performance. Apresenta a organização e seus valores. Disponível em: <http://www.performanceonline.com.br/>. Acesso em: 20 ago. 2012. POLANYI, M. The tacit dimension. Chicago: University Of Chicago Press; Revised ed. Edition, 2009. 128p

POPPER, M.; LIPSHITZ, R. Organizational learning mechanisms: a structural and cultural approach to organizational learning. Journal of Applied Behavioral Science, Thousand Oaks, v. 34, n. 2, p. 161-179, 1998.

RAGINS, B. R. Diversified mentoring relationships in organizations: a power perspective. Academy of Management Review, Briarcliff Manor, v. 22, n. 2, p. 482-521, 1997.

RAGINS, B. R.; COTTON, J. Mentor functions and outcomes: a comparison of men and women in formal and informal mentoring relationships. Journal of Applied Psychology, Washington, v. 84, n. 4, p. 529-550, 1999.

RAGINS, B. R.; COTTON, J.; MILLER, J. S. Marginal mentoring: the effects of type of mentor, quality of relationship, and program design on work and career attitudes. Academy of Management Journal, Briarcliff Manor, v. 43, n. 6, p. 1177-1194, 2000.

RAGINS, B. R.; KRAM, K. E. The roots and meaning of mentoring. RAGINS, B. R.; KRAM, K. E. The handbook of mentoring at work: theory, research, and practice. Thousand Oaks, CA: Sage Publications, 2007. p. 3-15.

REKHA, K.N; GANESH, M.P. Do mentors learn by mentoring others? International REAd | Porto Alegre - Vol. 23 - No Especial - Dezembro 2017 - p. 60-92 
Journal of Mentoring and Coaching in Education, Bingley, v. 1, n. 3, p. 205-217, 2012. SALAMAN, G. A response to snell the learning organization: fact or fiction? Human Relations, Thousand Oaks, v. 54, n. 3, p. 343-359, 2001.

SANTANA, R. S. C.; SOUZA-SILVA, J. C. A contribuição do modelo de excelência em gestão pública no processo de aprendizagem organizacional: o caso da Empresa Baiana de Águas e Saneamento S.A. Gestão e Sociedade, Belo Horizonte, v. 6, n. 13, p. 47-68, 2012. SANTOS, M. G. D.; JESUS, K. C. B.; SILVA, J. C. S.; RIVERA-CASTRO, M. A. Aprendizagem organizacional e suas modalidades: desenvolvendo a habilidade interpessoal nos programas trainees. Revista de Administração FACES Journal, Belo Horizonte, v. 14, n. 3, p. 94-113, 2015.

SCHEIN, E. H. Coming to a New Awareness of organizational culture. Sloan Management Review, Cambridge, v. 25, n. 2, p. 3-16, jan. 1984.

SCHEIN, Edgar H. Organizational culture. American Psychologist, Washington, v. 45, n. 2. p. 109-119, 1990.

SMITH-JENTSCH, K. A.; SCIELZO, S. A.; YARBROUGH, C. S.; ROSOPA, P. J. A Comparison of face-to-face and electronic peer mentoring: interactions with mentor gender. Journal of Vocational Behavior, Atlanta, v. 72, n. 2, p. 193-206, 2008.

SOUZA-SILVA, J. C. Condições e desafios ao surgimento de comunidades de prática em organizações. Revista de Administração de Empresas, São Paulo, v. 49, n. 2, p. 176-189, 2009.

SOUZA-SILVA, J. C. de. Aprendizagem organizacional. Desafios e perspectivas ao desenvolvimento de comunidades de prática. 1. ed. São Paulo: Conhecimento Superior, 2007. $320 \mathrm{p}$.

SWAP, W.; LEONARD, D.; SHIELDS, M.; ABRAMS, L. Using mentoring and storytelling to transfer knowledge in the workplace. Journal of Management Information Systems, Abingdon, v.18, n.1, p. 95-114, 2001.

TORBERT, W. The power of balance: Transforming self, society, and scientific inquiry. Thousand Oaks, CA: Sage, 1991. 304p.

WANG, C. L.; AHMED, P. K. Organisational learning: a critical review. The Learning Organization, Bingley, v. 10, n. 1, p. 8-17, 2003.

WENGER, E. Communities of practice: learning, meaning and identity.

Cambridge: Cambridge University Press, 1998. 336p.

YIN, R. K. Estudo de caso: planejamento e métodos. 4. ed. Porto Alegre: Bookman, 2010. REAd | Porto Alegre - Vol. 23 - No Especial - Dezembro 2017 - p. 60-92 
320p.

REAd | Porto Alegre - Vol. 23 - No Especial - Dezembro 2017 - p. 60-92 